\title{
An Experimental Study of Liquid-Solid Flow in a Circulating Fluidized Bed of Varying Liquid Viscosity
}

\author{
G. S. Nirmala ${ }^{1 \dagger}$ and L. Muruganandam ${ }^{2}$ \\ ${ }^{I}$ Chemical Engineering Division, School of Mechanical and Building sciences, VIT University, \\ Vellore-632014, India \\ 2 Chemical Engineering Division, School of Mechanical and Building sciences, VIT University, \\ Vellore-632014, India \\ $†$ Corresponding Author Email: gsnirmala@vit.ac.in
}

(Received January 2, 2014; accepted March 2, 2014)

\begin{abstract}
Hydrodynamics plays a major role in the design of an industrial liquid-solid circulating fluidized bed (LSCFB) system. Till date, research investigations have been carried out with tap water as a liquid phase in an LSCFB. But still there is a limited understanding regarding the circulation of particles in an LSCFB with viscous fluids. The aim of our study was to characterize the hydrodynamics in an LSCFB with varying viscosity. Experiments were conducted in a fluidized bed riser of $0.1 \mathrm{~m}$ diameter by $2.4 \mathrm{~m}$ height with different viscous liquids to study the effects of the operating parameters, namely, primary velocity, secondary velocity, and total velocity, on the hydrodynamic characteristics of the LSCFB with reference to its solid holdup, solid circulation rate, and particle velocity. Experiments were conducted using water and glycerol at different concentrations, and the solid particles (sand and resin) of different densities, but same diameter were used in the experiment. The results indicate that the solid holdup in the riser was axially uniform for viscous liquids, which increased with an increase in auxiliary velocity. The average solid holdup decreased with an increase in total velocity, and it increased with an increase in liquid viscosity as the critical transitional velocity decreased with an increase in viscosity. The solid circulation rate was found to be increased with increased total velocity, auxiliary velocity, and viscosity.
\end{abstract}

Keywords: LSCFB; Varying viscosity; Hydrodynamics; Solids circulation rate; Average solid holdup

\section{NOMENCLATURE}

$d_{p} \quad$ particle diameter (m)

$g \quad$ acceleration due to gravity $\left(\mathrm{m} / \mathrm{s}^{2}\right)$

$H \quad$ axial distance from bottom of the riser (m)

$U_{T} \quad$ total superficial liquid velocity $(\mathrm{m} / \mathrm{s})$

$U_{I} \quad$ primary or main liquid velocity $(\mathrm{m} / \mathrm{s})$

$U_{2} \quad$ secondary or auxiliary liquid velocity $(\mathrm{m} / \mathrm{s})$

$U_{t} \quad$ particle terminal velocity $(\mathrm{m} / \mathrm{s})$

$U_{s} \quad$ particle velocity $(\mathrm{m} / \mathrm{s})$
$G_{s} \quad$ solid circulation rate $\left(\mathrm{kg} / \mathrm{m}^{2} . \mathrm{s}\right)$

$\varepsilon_{s} \quad$ average solid holdup

$\ell s$ density of solids $\left(\mathrm{kg} / \mathrm{m}^{3}\right)$

$\ell l$ density of liquids $\left(\mathrm{kg} / \mathrm{m}^{3}\right)$

$\ell_{m}$ density of medium $\left(\mathrm{kg} / \mathrm{m}^{3}\right)$

$\mu_{1} \quad$ viscosity of water $(\mathrm{cP})$

$\Delta \rho$ density difference $\left(\rho_{\mathrm{s}}-\rho_{1}\right)\left(\mathrm{kg} / \mathrm{m}^{3}\right)$

\section{INTRODUCTION}

Liquid-solid circulating fluidized beds (LSCFBs) hold considerable promise as the ideal liquid-solid contactors. Due to its advantages such as effective solid-liquid contacting, maintaining uniform temperature, accommodating different particulate materials using high liquid throughputs, less back mixing, and improved heat transfer performances (Zhu et al. 2000) liquid-solid fluidized bed is used in the field of biochemical, environmental, metallurgical, and petrochemical engineering (Liang et al 1995, 1997; Lan, 2000, 2002a, $2002 \mathrm{~b})$.Lan et al $(2000,2000 \mathrm{a})$ reported the application of LSCFB for continuous protein recovery from whey solutions that contains a down comer for protein adsorption and a riser for protein desorption, with ion exchange particles circulating continuously between the 
riser and down comer.Liquid-solid circulating reactors form the heart of emerging alkylation processes for the production of motor fuel additives and also for the manufacture of linear alkyl benzene (LAB).Alkylation processes have been and continue to be a very important class of industrial reactions was studied by Liang et al (1995).A better understanding of this bed can be achieved by focusing on its hydrodynamic and transport phenomena. A typical LSCFB consists of a riser with primary and secondary flow, solid separator, and a down comer that feeds the solids to the riser. The hydrodynamic characteristics include flow regime, flow pattern at each phase, solid circulation rate, and solid holdup. In the past lot of work has been carried out on the hydrodynamics of LSCFB riser and its overall operation (Liang 1996, 1997; Zheng and Zhu 1999, 2000a, 2000b; Kuramoto, et al 1999). All the previous studies reported a uniform distribution of solid holdup in the axial direction, but a non-uniform radial distribution in the riser. In liquid-solid circulating systems, most particles in a riser tend to distribute uniformly in the axial direction. Heavy particles are distributed non-uniformly in the radial direction. It has been proved that lighter particles have a relatively flatter radial profile than that of heavier particles (Zheng et al 1999; Zheng and Zhu, 2000). The micro flow structures of LSCFB were characterized and compared with fast fluidization in the gas-solid circulating fluidized bed (CFB). The CFB regime is divided into two zones: the initial zone and the fully developed zone. The light particles always show axial uniformity in flow structure, but heavy particles show non-uniformity in the initial zone of the CFB. Vidhyasagar et al. (2008, 2009) observed the flow properties at various liquid velocities and solid inventory in the down comer at two different locations of the primary liquid distributor and also reported that the hydrodynamics of three experimental methods keeping the solid feeding structure similar. The effect of operating parameters, particle density, particle diameter, and the solid feed pipe diameter on the axial solid holdup distribution was analyzed by Natarajan et al. (2008a, $2008 \mathrm{~b}, 2009)$. The authors also studied the variation in liquid velocity on the flow characteristics, regime transition, and stable operating range of LSCFBs. Long and Zhu (2012) reported the effect of particle properties on solid holdup in the riser of LSCFB, based on three parameters, namely, superficial liquid velocity, normalized superficial liquid velocity, and the excess superficial liquid velocity; and it was also reported that excess superficial liquid velocity, more appropriate parameter, was used to evaluate the effect of particle properties on the solid holdup. The effect of liquid viscosity on hydrodynamics and transport properties of LSCFB was studied by few investigators with the riser operated in variable inventory modes (Cho et al., 2005; Shin et al., 2005; C. G. Lee et al., 2003; Y.Zheng. 2004). Cho et al.(2005) studied the liquid radial dispersion and observed a decrease in dispersion with an increase in liquid viscosity. Effect of liquid viscosity on fixed inventory mode was studied by Vidhyasagar et al. (2011) for different solid inventories and macroscopic flow properties such as pressure gradient, average solid holdup, axial solid holdup distribution, and solid circulation rate. In many applications, viscous liquids are used in industrial processes as processing fluids. The LSCFB with viscous fluids has a significant effect on determining the hydrodynamics and transport properties. The critical analysis of the literature indicates that the effect of liquid viscosity on hydrodynamics is not yet studied for the low-density particle resin.

Hence, an attempt has been made to study the effect of liquid viscosity, liquid flow rate on macroscopic flow properties namely average solid holdup, axial solid distribution, and solid circulation rate for water and glycerol-water solution.

\section{MATERIALS and METHOD}

The LSCFB consists of a riser column, liquid-solid separator, and down comer as depicted in Fig. 1. The riser has a diameter of $0.1 \mathrm{~m}$ and a height of $2.4 \mathrm{~m}$ with pressure tapings at regular intervals of $0.150 \mathrm{~m}$ and connected to a multi-limb manometer to measure the drop in pressure for each section of the riser. The base of the riser has two distributors; one for primary liquid flow and the other for auxiliary liquid flow into the riser. The liquid pumped from the reservoir consists of two streams, with the main stream entering the riser through the primary liquid distributor and the secondary stream through the auxiliary distributor, and each fitted to the respective distributors. The auxiliary liquid stream controls the quantity of particles by recirculating them from the storage vessel into the riser, as its function is to fluidize the particles at its base. When the secondary liquid flow rate was set to zero, no particles can enter the riser from the solid storage tank due to the high resistance caused by the particle layer at the bottom of the riser. When the combined velocities of the primary and auxiliary distributors are higher than the critical liquid velocity, it enables the particles to move concurrently to the top of the riser and then the particles are separated in the liquid solid separator. The separated solids return to the down comer through solids returning point and solid circulation rate measuring devices. The liquid is returned to the liquid reservoir which is pumped back to the riser.

In our study, the riser column was packed with particles to a known height and the primary liquid was added to the column through the flow meters at low intervals, till the bed expanded to its entire length. When the solids are about to entrain from the top of the riser, the secondary liquid was added and the circulation between the riser and the down comer was initiated. In a steady state, pressure drop was measured at different locations in the riser. The separated solids return to the down comer through the solids returning point and solid circulation rate measuring devices. The solid circulation rate device is calibrated to give the weight of solids circulated in a known time. The solid circulation rate was determined by closing the ball valve and observing the time required to accumulate the defined height of solids above the valve. The experiments were conducted with an increasing primary liquid velocity until the transport regime was reached, maintaining the secondary velocity as constant. The procedure was repeated for different constant secondary velocities by varying the primary velocity. Experiments were conducted with three different particles of different sizes and density, which were achieved by sieving and 


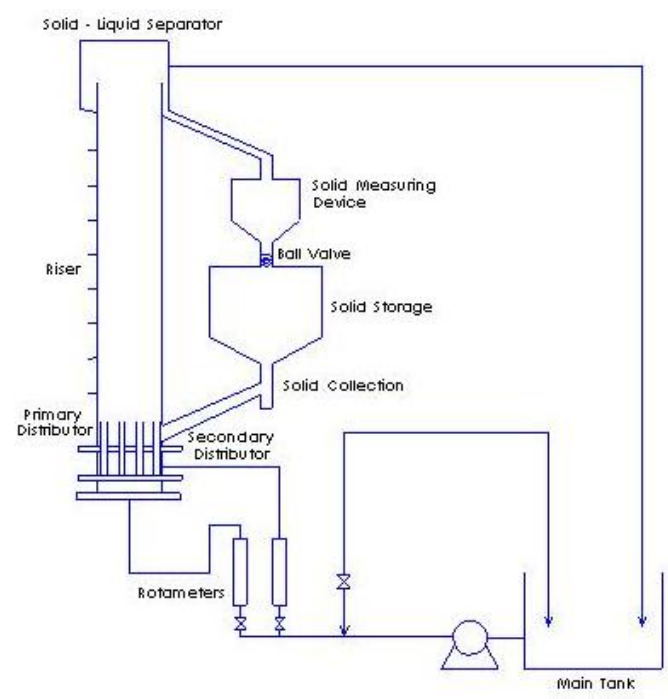

Fig. 1. Schematic of the experimental setup LSCFB

validating the particles to meet the standards. All the experiments were carried out at ambient temperature, and the solid holdup was measured by observing the pressure gradient at different locations in the riser. Average solid holdup was determined for each measured section using equation 1 and 2 neglecting the effect of wall friction.

$$
-\frac{\Delta P}{\Delta Z}=(1-\varepsilon)\left(\rho_{s}-\rho_{l}\right) g
$$

where $\varepsilon_{s}+\varepsilon_{l}=1$

$$
\varepsilon_{s}=\frac{h}{\Delta z} \frac{\left(\left(\rho_{m}-\rho_{l}\right)\right.}{\left(\rho_{s}-\rho_{l}\right)}
$$

Resin and sand with an average diameter of $0.5 \mathrm{~mm}$ and a density of $1,400 \mathrm{~kg} / \mathrm{m}^{3}$ and $2,400 \mathrm{~kg} / \mathrm{m}^{3}$, respectively, were used as dispersed phase. Tap water and aqueous glycerol were used as the continuous phase.

The physical properties of the liquid used in the present study are shown in Table 1 and the maintained operating conditions are shown in Table II.

Table 1 Physical property of the liquids and solids used in the present study

\begin{tabular}{|c|c|c|c|c|}
\hline $\begin{array}{c}\text { Fluidizing } \\
\text { liquid }\end{array}$ & $\begin{array}{c}\text { Density } \\
\left(\mathrm{Kg} / \mathrm{m}^{3}\right)\end{array}$ & $\begin{array}{c}\text { Viscosity } \\
(\mathrm{cp})\end{array}$ & $\begin{array}{c}\text { Terminal velocity } \\
\text { of resin particles } \\
(\mathrm{m} / \mathrm{s}) \mathrm{U}_{\mathrm{t}}\end{array}$ & $\begin{array}{c}\text { Terminal } \\
\text { velocity of } \\
\text { sand particles } \\
(\mathrm{m} / \mathrm{s}) \mathrm{U}_{\mathrm{t}}\end{array}$ \\
\hline Tap water & 1000 & 1 & 0.03064 & 0.0700 \\
\hline $\begin{array}{c}5 \text { vol \% } \\
\text { aqueous } \\
\text { glycerol }\end{array}$ & 1011 & 1.085 & 0.02973 & 0.0675 \\
\hline $\begin{array}{c}15 \text { vol \% } \\
\text { aqueous } \\
\text { glycerol }\end{array}$ & 1036 & 1.36 & 0.02733 & 0.0614 \\
\hline
\end{tabular}

$\mathrm{U}_{\mathrm{T}}=\mathrm{U}_{1}+\mathrm{U}_{2}$ $u_{t}=\left[\frac{4 d_{p}\left(\rho_{s}-\rho_{g}\right) g}{3 \rho_{g} C_{D}}\right]^{1 / 2}$

Table 2 Operating conditions maintained

\begin{tabular}{|l|l|}
\hline \multicolumn{1}{|c|}{ Variables } & \multicolumn{1}{|c|}{ Range } \\
\hline $\begin{array}{l}\text { Primary liquid velocity, } \\
\mathrm{U}_{1} \mathrm{~m} / \mathrm{s}\end{array}$ & $\begin{array}{l}0.0106-0.046001(\text { resin) } \\
0.02477-0.099 \text { (sand) }\end{array}$ \\
\hline $\begin{array}{l}\text { Auxiliary liquid } \\
\text { velocity, } \mathrm{U}_{2} \mathrm{~m} / \mathrm{s}\end{array}$ & $\begin{array}{l}0.0141-0.02477 \text { (resin) } \\
0.028-0.04954 \text { (sand) }\end{array}$ \\
\hline $\begin{array}{l}\text { Total Liquid velocity, } \mathrm{U}_{\mathrm{T}} \\
\mathrm{m} / \mathrm{s}\end{array}$ & $\begin{array}{l}0.02477-0.06723 \text { (resin) } \\
0.056-0.1415 \mathrm{~m} / \mathrm{s} \text { (sand) }\end{array}$ \\
\hline Viscosity of liquid, $\mathrm{cP}$ & $1.00-1.36$ \\
\hline Particle density $\left(\mathrm{kg} / \mathrm{m}^{3}\right.$ ) & $\begin{array}{l}1400(\mathrm{resin}) \\
2400(\mathrm{sand})\end{array}$ \\
\hline
\end{tabular}

\section{Results AND Discussion}

AThe visual observation of liquid-solid circulating fluidized was possible as the test section was made of acrylic. The experimental data of the present study cover a wide range of average solid holdup $\varepsilon_{\mathrm{s}}$, the solid circulation rate $G_{s}$, and solid velocity $U_{s}$ in the circulating fluidized regime. All these parameters are controlled by adjusting the ratio of primary and secondary flow rate and hence the auxiliary distributor and the solid feeding pipe acts as a non-mechanical valve. For the low-density particle (resin) at higher liquid velocities with particle feeding at the bottom of the riser, it has been noted that particles are entrained by the liquid in the fully developed zone with a smooth and particulate type of fluidization.

\subsection{Average Solid Holdup}

\subsubsection{Effect of auxiliary velocity on average solid holdup}

The effect of auxiliary velocity on solid holdup for solidwater system was studied by many authors (Liang et al. 1997; Zheng et al. 1997; Kuramo et al. 1999; Zhu et al. 2000; Vidyasagar et al. 2008; Natarajan et al. 2008a, 2009; Rao et al. 2007). The variation of solid holdup in the riser with the change in total velocity, maintaining auxiliary velocity as constant for resin-water system and sand-water system is shown in Fig. 2a and 2b. In the present study it is shown that, for the given auxiliary velocity solid holdup decreases with the increase in primary and total velocity, and it is also observed that the solid holdup increases in the riser with an increase in auxiliary velocity. This is due to the fact that at low auxiliary velocities there will be slow movement of solids in the return pipe with the slow loading of solid into the riser. The increase in the auxiliary velocity increases the flow of solids into the return pipe. On the other hand it is also observed that at a fixed auxiliary velocity, solid holdup decreases rapidly with an 
increase in the total velocity which is termed as initial circulating zone. At higher total velocity, solid holdup shows a plateau phase which indicates that the solid flow enters into the fully developed zone.

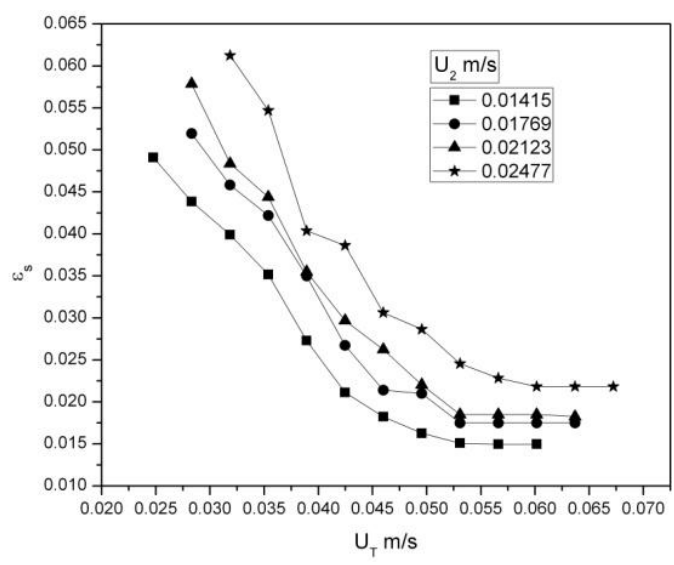

Fig. 2a. The effect of total velocity on average solid holdup for resin-water system

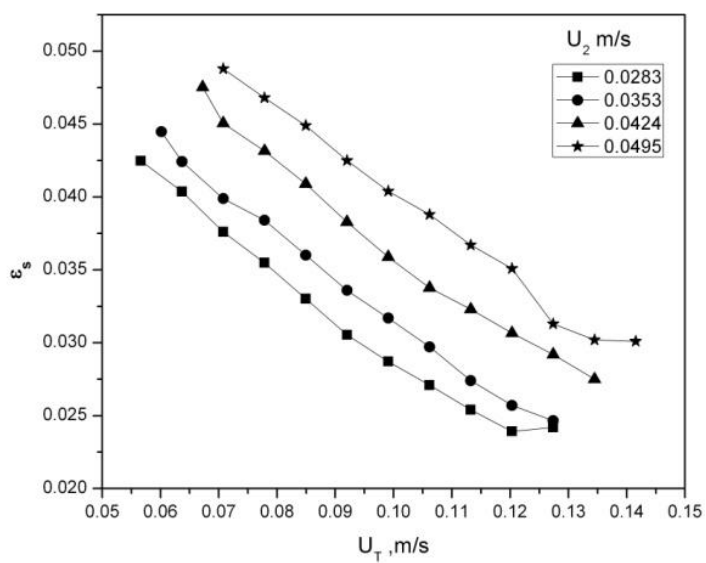

Fig. 2b. The effect of total velocity on average solid holdup for sand-water system

\subsubsection{Effect of liquid viscosity on solid holdup}

The effect of liquid viscosity on solid holdup is shown in Fig. 3a for resin glycerol system and Fig. 3b for sand glycerol system. From Fig. $3 a$ and $3 b$ it is evident that with an increase in total velocity or primary velocity decreases the solid holdup initially and at higher total velocity to a minimum value as reported in Fig. 2a and $2 \mathrm{~b}$ for water system maintaining auxiliary velocity as constant. The initial rapid decrease corresponds to rapid increase in solid circulation rate with the increase in total velocity, while the minimum value corresponds to higher increase in solid circulation rate. This is due to the fact that increase in liquid velocity increases the solid velocity thereby decreasing the residence time of the solid and solid holdup in the riser. Also, more uniform solid holdup profiles was observed in the developed zone than the initial zone. Solid holdup is maximum when the liquid velocity is minimum, corresponding to the circulation of solids in the LSCFB.
An increase in auxiliary velocity increases the input of solid into the riser and increases the solid hold up $\varepsilon_{\mathrm{s}}$.

It is also observed that for the same set of auxiliary liquid velocity of water system, an increase in solid holdup was observed with increasing viscosity of

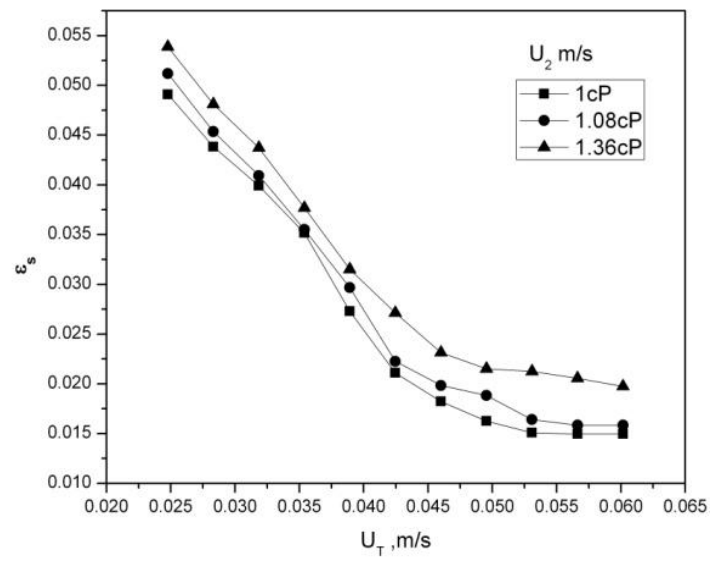

Fig. 3a. The effect of viscosity on average solid holdup for resin-glycerol system

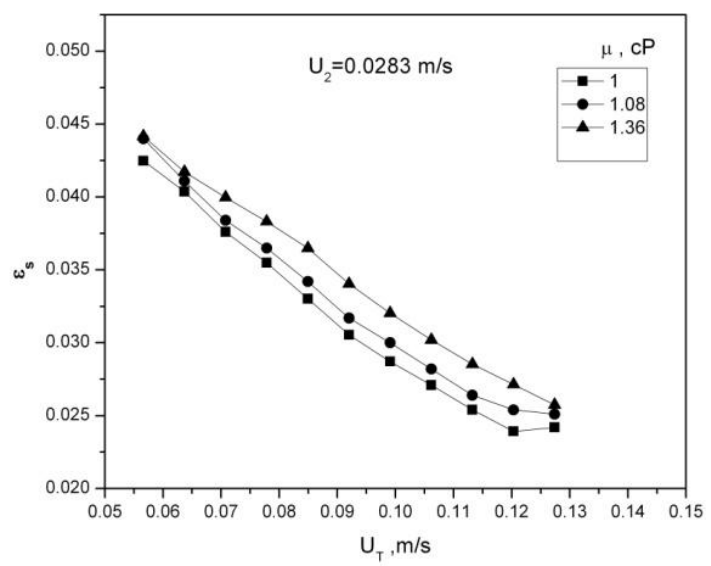

Fig. 3b. The effect of viscosity on average solid holdup for sand-glycerol system

liquid. For the given total liquid velocity, for all the particles the average solid holdup decreases with the increase in superficial total velocity. As more particles are entrained which in turn shows lower solid concentration but, with increase in viscosity solid holdup is found to be increased. As it is evident from Fig. $3 a$ and $3 b$, the increase in solid holdup is due to the fact that circulating fluidization regime starts much earlier for viscous system as its terminal velocity decreases with the increase in viscosity. In turn there will be a decrease in the critical transitional velocity with the increase in liquid viscosity. The mobility of the fluidizing solids decreases with the increasing liquid viscosity upto $1.36 \mathrm{cP}$ and hence higher solid holdup exists in the riser. This observation is similar to the result obtained by Vidyasagar et al. (2011) for glass beads of $1.36 \mathrm{~mm}$ diameter. 


\subsubsection{Effect of density on the solids}

There is no information available from the literature on the effect of liquid viscosity for solids of different density and same size on solid holdup. Fig. 4 shows the effect of solid density on solid holdup for total liquid velocities at constant auxiliary velocity. It is observed

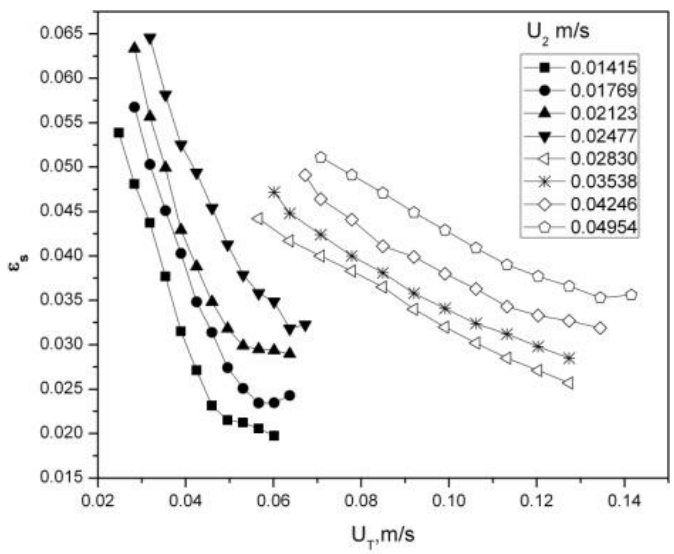

Fig. 4. Effect of density of particle on the variation of solid holdup with variation in total velocity

from the Figure 4 that with the decrease in solid density, the solid holdup is shifted towards left indicating that the solid circulation begins at lower velocity corresponding to its terminal velocity and solid holdup was found to be higher for low liquid velocity. The operating range for liquid velocity for lighter particles is shorter than sand due to the sharp decrease in solid holdup from region 1 to 2 for resin, whereas for heavier particle the decrease in solid holdup with liquid velocity is gradual from region 1 to 2. Concisely, it is observed that the decrease in density decreases the solid holdup with increase in liquid velocity more rapidly. These results are consistent to the previous observation reported by Natarajan et al. (2008a) for water system using silica gel and resin. For the given fluid with viscosity1.36 $\mathrm{cP}$ for resin and sand of $0.5 \mathrm{~mm}$ it is observed that there is a considerable height of dense phase at the bottom of test section for all operating conditions maintained in the test section. In case of low dense particle resin, no dense phase was observed at the bottom of the test section. For heavy solid particles, the gravitational force is more predominant and the particles have to accelerate initially so as to reach the fully developed regime, since the contribution of drag is balanced by the gravitational component on the particles. As the density ratio $\left(\left(\rho_{\mathrm{s}-} \rho_{1}\right) / \rho_{1}\right)>1$, there exists accelerating or dense regime at the bottom of the test section (Rao et al. 2007).

\section{2. Solid Circulation Rate}

Solid circulation rate referred in the text is obtained using

$G_{s}=\frac{W_{s}}{A}$

Where superficial solid velocity is
$U_{s}=\frac{G_{s}}{\rho_{s}}$

As represents area of the riser cross section

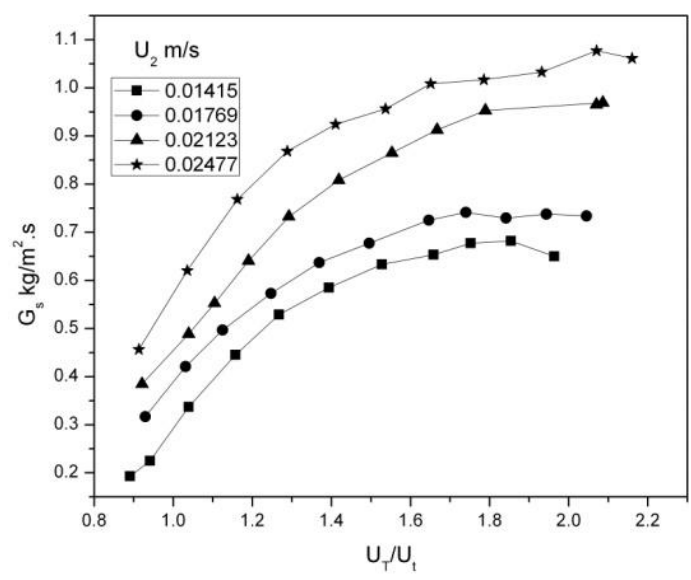

Fig. 5a. The effect of total velocity on solid circulation rate for resin-water system

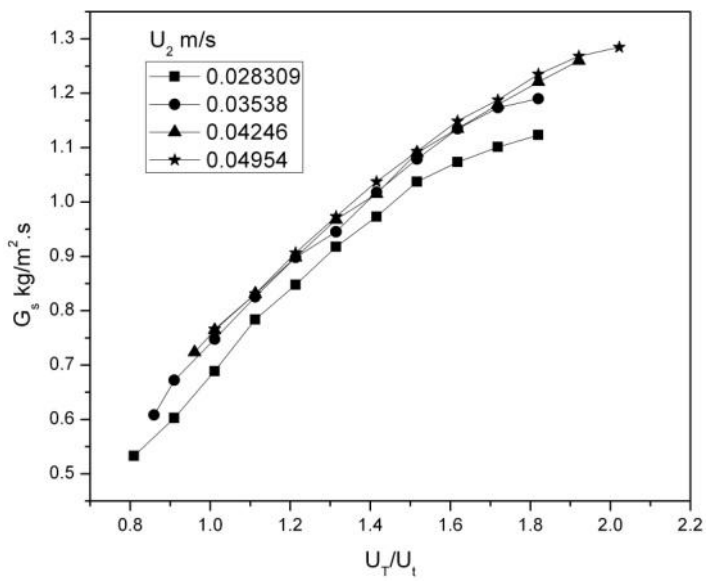

Fig. 5b. The effect of total velocity on solid circulation rate for sand-water system

\subsubsection{Effect of variation of solid circulation rate with the ratio $U_{T} / U_{t}$}

Figure $5 \mathrm{a}$ and $5 \mathrm{~b}$ also indicates the variation of solid circulation rate with normalized liquid velocity $\left(\mathrm{U}_{\mathrm{T}} / \mathrm{U}_{\mathrm{t}}\right)$ for resin and sand. Quantity of the solids fed and the total liquid velocity were the variables affecting solid circulation rate in a circulating fluidized bed. It is interesting to observe the variation in solid circulation rate shows similar trends for both resin and sand. For a given total velocity, solid circulation rate increases with the increase in auxiliary liquid velocity, as more solids were introduced into the riser from the down comer as its function is to regulate the solid flux. The data show that the increase in auxiliary velocity, solid circulation rate curve increases steeply at low liquid velocity and then at higher liquid velocity, solid circulation rate was insignificant. It is also reported that the increase in solid velocity with liquid velocity was observed in two 
regions. In region 1 , solid velocity increases rapidly with increasing velocity followed by region 2 , in which solid velocity increases insignificantly, which is also reported

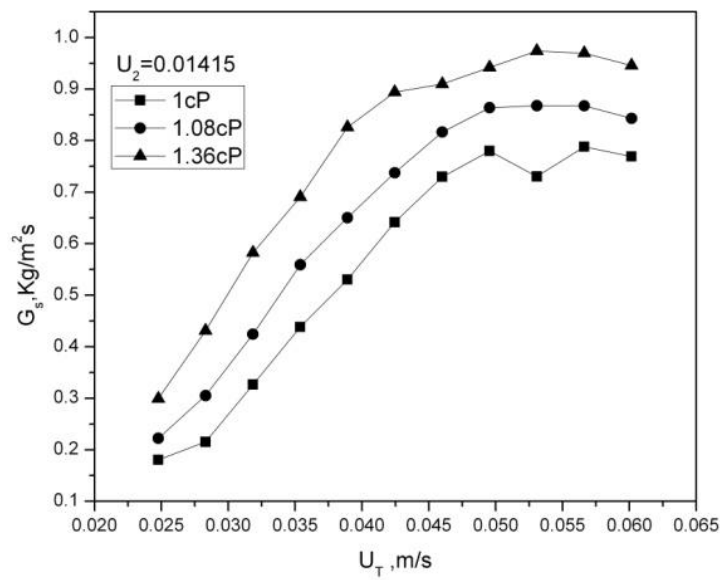

Fig. 6a. The effect of viscosity on solid velocity for resin-glycerol system

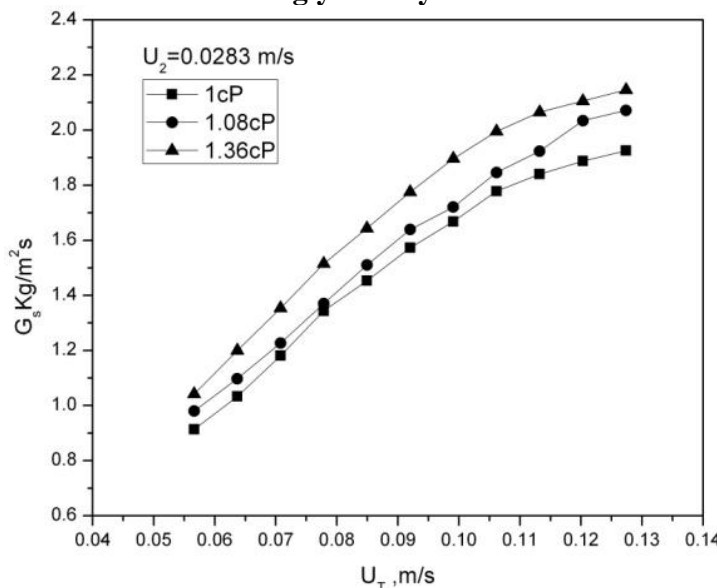

Fig. 6b. The effect of viscosity on solid velocity for sand-glycerol system

by previous researchers for water system (Lan et al. 2000; Natarajan et al. 2008b; Vidyasagar et al. 2008).

The critical transition velocity for low dense particle was found to be lesser than the heavier dense particle. Lighter dense particles have low terminal velocity resulting in early circulation of solids. The transition from region 1 to region 2 is sharper for low density particle. Zheng and Zhu (2001) experimentally determined the critical transitional velocity and related the onset velocity to the terminal velocity of the particles as $\mathrm{U}_{\mathrm{cf}}=1.1 \mathrm{U}_{\mathrm{t}}$. Natarajan et al. (2008b) experimentally studied the effects of particle size, density, and variation of liquid velocity on the flow characteristics. Based on the study, LSCFB is divided into two zones: region 1 varies from particle terminal velocity, $\mathrm{U}_{\mathrm{t}}$ to $1.3 \mathrm{U}_{\mathrm{t}}$ and region 2 varies from $1.3 \mathrm{U}_{\mathrm{t}}$ to $2.1 \mathrm{U}_{\mathrm{t}}$. The velocity at which change in initial zone to circulating zone plays a guideline to design a liquid-solid circulating fluidized bed. In this study, the variation from initial zone to circulating zone occurs approximately at total liquid velocity of 1.33 times the terminal velocity of the particle.

\subsubsection{Effect of liquid viscosity on solid circulation rate}

The variation of solid circulation rate with the total liquid velocity for viscosity of $1.36 \mathrm{cP}$ for resin glycerol and sand-glycerol system showed the similar results as noticed for water system with a rapid increase in solid velocity with increase in total velocity and then plateaus in the fully developed zone.

The variation of solid circulation rate with total liquid velocity and viscosity as parameters is shown in Fig. 6a and $6 \mathrm{~b}$ for resin and sand glycerol system, respectively. With increase in viscosity from 1 to $1.36 \mathrm{cP}$ the solid circulation rate curve shift towards left indicating the solid velocity higher for viscous solution than for water. This increase in solid circulation rate with the increase in viscosity is due to decrease in terminal settling velocity which in turn decreases the critical transitional velocity therefore circulating fluidization regime starts earlier for viscous systems.

Effect of liquid viscosity studied by Vidyasagar et al. (2011) for glass beads-glycerol system shows a similar prediction.

\section{Conclusion}

The average solid holdup and solid circulation rate for sand and resin of $0.5 \mathrm{~mm}$ diameter were studied in a liquid-solid circulating fluidized bed. The average solid holdup decreased, when the primary or total velocity was increased and found to increase with increase in auxiliary and viscosity of the liquid from 1 to $1.36 \mathrm{cP}$. This is due to the fact that the increase in liquid velocity increases the solid velocity thereby decreasing the residence time of the solid and solid holdup in the riser. Solid circulation rate was found to be increased with the increase in total velocity steeply at low liquid velocity and insignificant at higher liquid velocity.

The study identifies that with decrease in density of solid the solid curve shift towards left showing higher solid velocity at low total liquid velocity for resin of lower density. The transition from conventional fluidization to circulating fluidization occurs at high liquid velocity and it is more gradual for heavier particles. The velocity at which change in initial zone to circulating zone takes place in the current study is approximately at total liquid velocity around 1.33 times the terminal velocity of the particle. On the basis of normalized liquid velocity, the critical transitional velocity for all the particle are approximately 1 and for low dense particle resin is found to be lower than sand as its terminal velocity is low.

\section{REFERENCES}

Cho Y. J., P. S. Song and C. G. Lee (2005). Liquid radial dispersion in liquid solid circulating 
G. S. Nirmala and L. Muruganandam / JAFM, Vol. 8, No. 1, pp. 95-101, 2015.

Fluidized beds with viscous liquid medium, Chem. Eng. Commun., 192, 257-271.

Kuramoto K., K. A. Tsutsumi and T. Chiba (1999). High-Velocity Fluidization of solid particles in a liquid solid circulating Fluidized bed system, Can. J. Chem. Eng., 77, 291-298.

Lan Q., J. X. Zhu, A. S. Bassi, A. Margaritis and Y. Zheng (2000). Continuous Protein recovery using a Liquid-Solid Circulating Fluidized Bed Ion exchange system: Modelling and Experimental studies, Can. J. Chem. Eng., $78,858-866$.

Lan Q., A. S. Bassi, J. X. Zhu and A. Margaritis (2002a). Continuous Protein recovery with a Liquid-Solid Circulating Fluidized Bed Ion exchanger, AIChEJ., 48(2), 252-261 .

Lan Q., A. S. Bassi, J. X. Zhu and A. Margaritis (2002b). Continuous Protein recovery from Whey Using with a Liquid-Solid Circulating Fluidized Bed Ion exchange Extraction, Biotechnol. Bio-eng., 78(2), 157-163.

Lee C. G., S. H. Kang, K. S. Shin, P. S. Song, Y. Kang and S. D. Kim (2003). Effects of liquid viscosity on the solid holdup and Heat transfer Coefficient in the riser of liquid solid circulating Fluidized beds, Hwahak Konghak, 41(4), 524-529.

LiangW. G., Q. Yu, Y. Jin, Z. W. Wang, Y. Wang, M. He and E. Min (1995). Synthesis of Linear Alkyl Benzene in a Liquid Solid Circulating Fluidized bed reactor.J. Chem. Tech. Biotech, 62,98-102.

Liang W. G., J. X. Zhu, Y. Jin, Z. Q. Yu, Z. W. Wang and J. Zhou (1996). Radial non uniformity of flow in a Liquid solid circulating Fluidized bed, Chem. Eng. Sci., 51,2001-2010.

Liang W. G. and J. X. Zhu (1997). Effect of radial Flow non uniformity on the Alkylation reaction in a Liquid solid circulating Fluidized bed (LSCFB) Reactor, Ind. Eng. Chem. Res., 36, 4651-458.

Liang W. G., S. L. Zhang, J. X. Zhu, Y. Jin, Z. Q. Yu and Z.W. Wang (1997). Flow characteristics of the liquid solid circulating Fluidized bed, Powder Technol.,90, 95-102.

LongS., and Zhu, J. (2012). Experimental investigation of the effects of particle properties on solid hold-up in an LSCFB riser, Chem. Eng. J., 197, 322-329.

Natarajan P., R. Velraj and R. V. Seeniraj (2008a). Effect of various parameters on the solid holdup in a liquid solid circulating Fluidized bed, Int. J. Chem. Eng. React. Eng. 6,1-29.
Natarajan P., R.Velraj and R.V.Senniraj (2008b). Effect of various parameters on the solid circulation rate in a Liquid-solid circulating fluidized bed, AsiaPac.J.Chem. Eng., 3, 459-470.

Natarajan P, R.Velraj and R.V.Seeniraj (2009). Studies on regime transition, operating range and system stability in a liquid solid circulating fluidized bed,Chem Eng. Technol. 32, 572-579.

Rao B., V. V. C. Sailu, and D. K. Sandilya (2007). An experimental study of liquid particle flow in circulating fluidized bed,Chem. Eng. Commun., 194, 353-367.

Shin K. S., P. S. Song, C. G. Lee, S. H. Kang, Y. Kang, S. D. Kim and S. J. Kim (2005). Heat transfer coefficient in viscous liquid -solid circulating Fluidized beds, AIChE J., 51, 671-677.

Vidyasagar S., S. K, Krishnaiah and P. S. T. Sai (2008). Hydrodynamics of liquid solid Circulating Fluidized bed: Effect of dynamic leak, Chem. Eng. J., 138, 425-435.

Vidyasagar S., K. Krishnaiah and P.S.T. Sai (2009). Comparison of Macroscopic flow properties obtained by three different methods of operation in a Liquid solid circulating Fluidized beds, Chem. Eng. Process., 48, 259 -267.

Vidyasagar S., K. Krishnaiah and P. S. T. Sai (2011). Macroscopic properties of liquid solid circulating fluidized bed with viscous liquid medium, Chem. Eng. Process.,5042-52.

Zheng Y., J. X. Zhu, J. Wen, S. Martin, A. Bassi and A. Margaritis (1999). The Axial hydrodynamic behavior in a liquid solid circulating Fluidized bed,Can. J. Chem. Eng., 77, $284-290$.

Zheng Y. and J. X. Zhu (2000a). Microstructural Aspects of the Flow Behaviour in a Liquid -Solid Circulating Fluidized bed, Can. J. Chem Eng., 78(2),75-81.

Zheng Y. and J. X. Zhu (2000b). Overall pressure and system stability in a liquid solid circulating fluidized bed, Chem. Eng. J. 79, 145 -153.

Zheng Y. and J. X. Zhu (2001). The onset velocity of a Liquid solid circulating fluidized bed.Powder Technol, 114, 244 -251.

Zheng Y. (2004). Radial particle profiles in a liquidsolid CFB with varying viscosity, Chem.Eng.Tech., 27, 769-776.

Zhu J. X, Y. Zheng, D. G. Karamanev and A. S. Bassi (2000). (Gas)-Liquid solid circulating Fluidized beds and their potential applications to Bioreactor Engineering.Canadian journal of Chemical Engineering, 78, 82-94. 